\title{
Comparative Analysis of Lithium First Wall Concepts for Tokamak with Reactor Technologies
}

\author{
A. V. Vertkov ${ }^{a, b}$, M. Yu. Zharkov ${ }^{a, b}$, I. E. Lyublinskii ${ }^{a, b, c, *}$, and V. A. Safronov ${ }^{b}$ \\ ${ }^{a}$ Krasnaya Zvezda Corporation, Moscow, 125284 Russia \\ ${ }^{b}$ Institution “Project Center ITER,” Moscow, 123182 Russia \\ ${ }^{c}$ National Research Nuclear University Moscow Engineering Physics Institute, Moscow, 115409 Russia \\ *e-mail: IELyublinskiy@redstaratom.ru \\ Received April 9, 2021; revised May 25, 2021; accepted June 2, 2021
}

\begin{abstract}
When developing the stationary fusion reactor, an unresolved issue is the design of its intra-chamber plasma-facing elements. It has now become obvious that among the materials conventionally used for intra-chamber elements, there are no solid structural materials that would meet the requirements for the long-term operation under the effect of the flux of fusion neutrons (14 MeV) with a density of $\sim 10^{14} \mathrm{~cm}^{-2} \mathrm{~s}^{-1}$ and the heat flux with a power density of $10-20 \mathrm{MW} / \mathrm{m}^{2}$. An alternative solution to this problem is the use of liquid metals as a plasma-facing materials, and, first of all, the use of lithium, which has a low atomic number (low charge number $Z$ ). Other easily-melting metals are also considered, which have higher $Z$ number, but lower saturation vapor pressure than lithium. This will make it possible to create the long-lived, heavy-todamage and self-renewing surface of the intra-chamber elements, which will not contaminate the plasma. The main ideas of the alternative concept of the intra-chamber elements can be formulated based on the comprehensive analysis of the problems and requirements arising during the development of intra-chamber elements of the stationary reactor, for example, the DEMO-type reactor. The article presents the analysis of the possible design of the lithium-coated intra-chamber elements and discusses the main ideas of the lithium first wall concept for the tokamak with reactor technologies.
\end{abstract}

Keywords: lithium, liquid metals, divertor, limiter, first wall

DOI: $10.1134 / \mathrm{S} 1063780 \mathrm{X} 21110258$

\section{INTRODUCTION}

When developing the stationary fusion reactor, an unresolved issue is the design of its intra-chamber plasma-facing elements (ICEs). It has now become obvious that among the materials conventionally used for ICEs, there are no solid structural materials that would meet the requirements for the long-term operation under the effect of the flux of fusion neutrons $\left(14 \mathrm{MeV}\right.$ ) with a density of $\sim 10^{14} \mathrm{~cm}^{-2} \mathrm{~s}^{-1}$ and the heat flux with a power density of $10-20 \mathrm{MW} / \mathrm{m}^{2}$.

An alternative solution to this problem is the use of liquid metals (LMs) as a plasma-facing materials, and, first of all, the use of lithium, which has the low atomic number (low charge number $Z$ ). Other easy-melting metals are also considered, which have the higher $Z$ number, but the lower saturation vapor pressure than lithium. This will make it possible to create the long-lived, heavy-to-damage and self-renewing surface of the intra-chamber elements, which will not contaminate the plasma.

The main ideas of the alternative ICE concept can be formulated based on the comprehensive analysis of the problems and requirements arising during the development of ICEs of the stationary reactor, for example, the DEMO-type reactor [1,2]. It is also necessary to take into account the modern experience and achievements in the fields of design, material science and technology of structural materials, as well as the distinctive features of using LMs in the fusion facilities with magnetic plasma confinement [3-8]. The article presents the analysis of possible design of the lithiumcoated ICEs and discusses the main ideas of the lithium first wall concept for the tokamak with reactor technologies (TRT) [9].

\section{COMPARATIVE ANALYSIS OF TRT LITHIUM FIRST WALL CONCEPTS}

The most important issue, which is the main point of the concept, is the choice of the scheme for using the LMs. There are four main approaches to the ICE protection using the LMs: the thick fast-flowing film; the thin slowly flowing film; the film slowly flowing through the capillary porous system (CPS) and the protection using the LM vapor. It is fundamentally important that the concept should be promising to be used in the stationary tokamak reactor. Therefore, this 

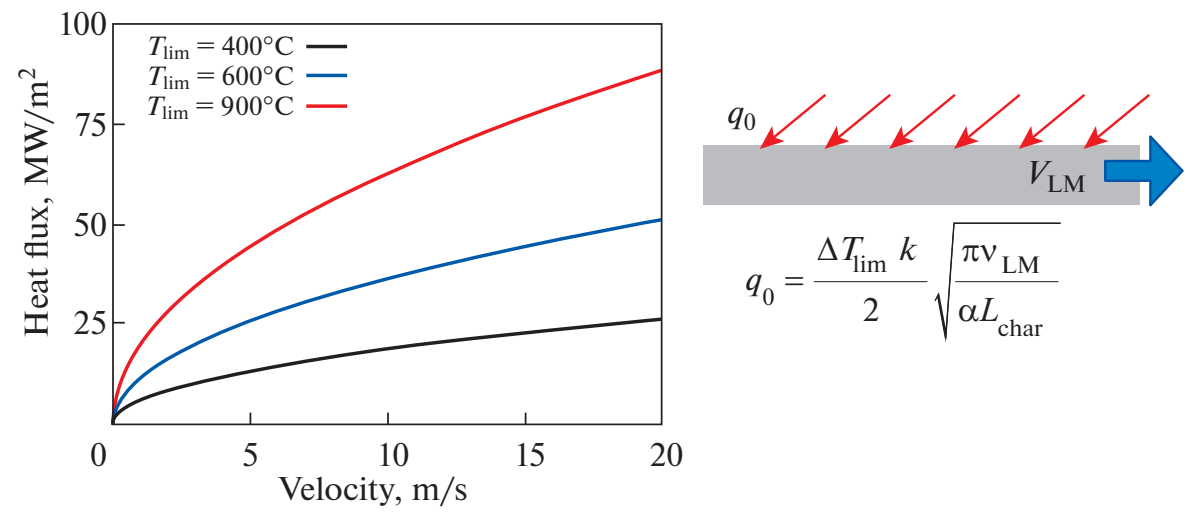

Fig. 1. Results from calculations of removed heat flux as a function of the LM velocity of flow at surface temperatures $T_{\text {lim }}=400$, 600 , and $900^{\circ} \mathrm{C}$.

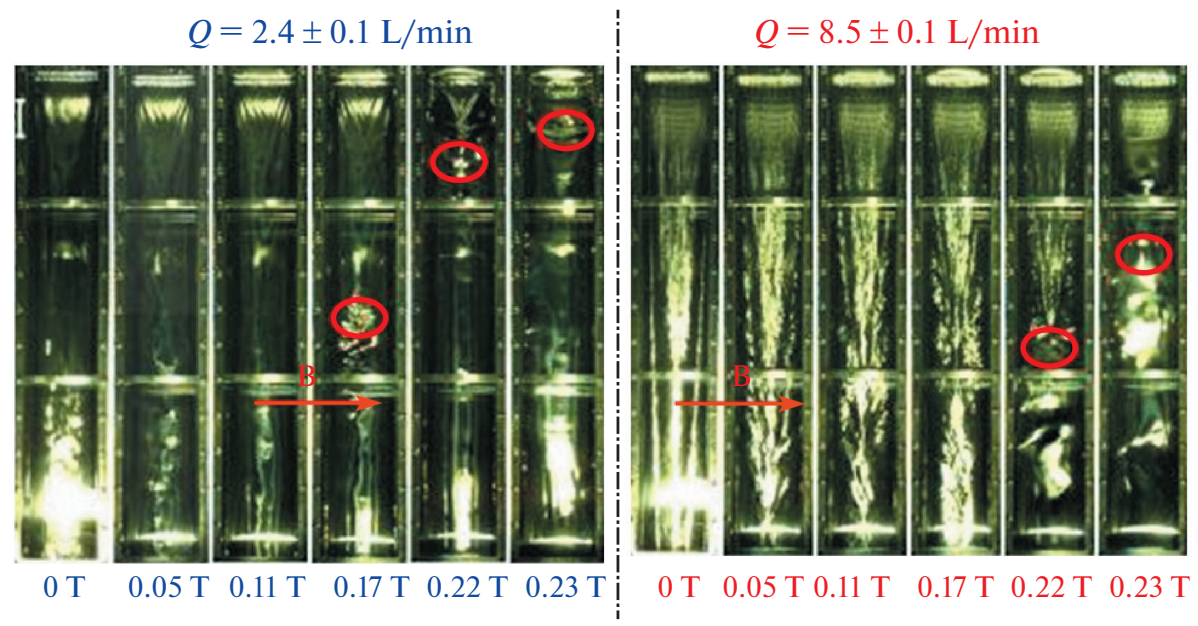

Fig. 2. Flow of liquid lithium in transverse magnetic field created at experimental stand. Areas corresponding to stopped lithium flow are marked with ovals [10].

review does not consider in detail the existing variety of schemes suitable only for the experimental physical facilities.

The first approach, proposed in the USA, assumes the provision of heat and particle removal due to the flow of a thick LM layer (more than $1 \mathrm{~cm}$ ) over the ICE surfaces. However, in order to perform the declared functions, the high velocity of LM flow (more than $10 \mathrm{~m} / \mathrm{s}$ ) is required at heat fluxes of up to $10 \mathrm{MW} / \mathrm{m}^{2}$ from the plasma (Fig. 1). The high MHD resistance to the LM flow in the magnetic field makes it impossible to implement this approach. As has been shown experimentally (Fig. 2) [10], at a velocity of $0.3-1.2 \mathrm{~m} \mathrm{~s}^{-1}$, the lithium flow stops propagating at a transverse magnetic field of $0.2-0.3 \mathrm{~T}$. In addition, it is difficult to ensure the uniform coating of the ICE surfaces and to provide the necessary resistance to the LM sputtering under the action of MHD forces. Faced with insurmountable problems, the development of this direction was suspended.

The second concept, which is now being intensively developed in the United States and under their influence, in the People's Republic of China (PRC), consists in organizing the slow flow of a thin liquid metal film over the ICE surfaces for their protection and self-renewal. Heat removal is provided by the thermal conductivity: the ICE structure transports heat to the flowing coolant [11]. In this case, the stabilization of surface temperature strongly depends on the ICE design and materials used, as well as on the coolant properties. For such a concept, the main problems consist in forming the uniform coverage of the ICE surface with the LM film and the LM sputtering under the action of MHD forces. When solving these problems, the developers had to use the approach developed in Russia and based on the capillary effect. In the USA, they try to supply LM and distribute it 

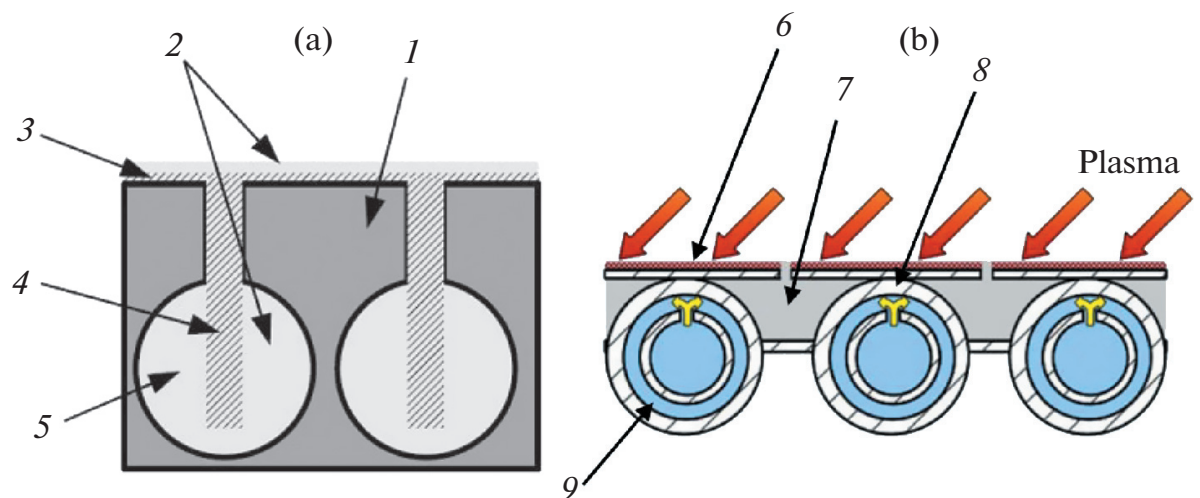

(c)

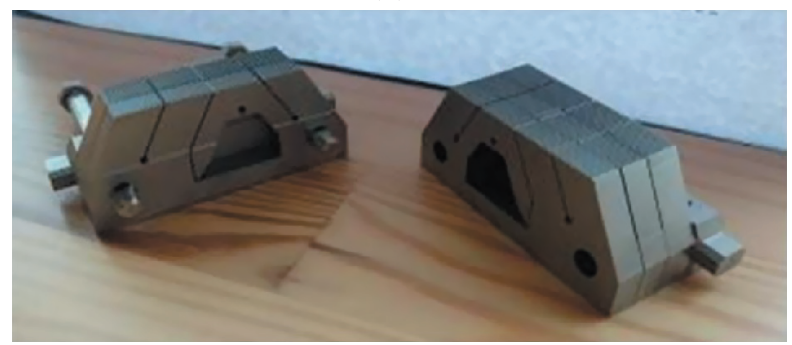

Fig. 3. Scheme and model of ICE with LM coating used at the NSTX-U tokamak: (a) scheme without active cooling with CPS-based lithium feeding; (b) ICE model tested at the Pilot-PSI facility; and (c) scheme of T-shaped ICE for the DEMO stationary tokamak reactor with active cooling. (1) ICE base, (2) liquid metal, (3) textured surface, (4) inner capillary structure, (5) inner reservoir, (6) porous or textured surface, (7) liquid lithium, (8) structural material (e.g., F82H steel), and (9) coolant (e.g., helium).

over the ICE surface using the millimeter-sized channels (grooves) made on the structure surface. In PRC, in addition to this, a woven mesh is used. An example of this approach implementation is the design of ICEs for the NSTX-U (Fig. 3) and EAST (Fig. 4) tokamaks. The experiments show (Fig. 5) [12] that the positive to a certain extent result in terms of formation of the uniform LM flow distribution over the surface can be achieved only when using the capillary effect (application of small scratches, grooves or meshes, or deposition of porous powder layers).

The third concept developed in Russia is based on using the stationary or slowly flowing LM enclosed in the porous structure of the CPS [13]. This concept seems to be the most successful solution to the problem of protecting the ICE surfaces. It integrates all the advantages of using the LMs with the possibility of uniformly distributing the LM layer on the ICE surface, regardless of its orientation in space, the resistance to LM sputtering being high. Heat removal is ensured by thermal conductivity: the ICE structure transports heat to the flowing coolant. Thus, the ability of the CPS-based ICEs to withstand the heat fluxes of high specific density strongly depends on their design and construction materials and coolant used.
Our first experiments performed with lithium flowing over the CPS panel [14] confirm the realizability of the concept being developed.

The second and third concepts are close enough. In the future, they can become the unite concept, since the solution to their critical problems is based on the use of the capillary effect with the help of the CPS.

Based on the existing analytical reviews and our own experience $[3-8,15]$, we believe that the most reasonable scheme consists in using the slow drift of liquid metal over the CPS porous surface or directly inside its structure. This scheme provides for the selfrenewal of the ICE surface of any shape and orientation and the LM stabilization in relation to the effect of the electromagnetic forces due to the capillary forces acting in the CPS. The liquid metal slowly flowing under the action of gravity (at the velocity not more than a few millimeters per second) will remove the trapped tritium and accumulated impurities. Moreover, there is no need to permanently "pour" the LM. This operation can be performed periodically when the predetermined concentration of tritium in lithium is reached or when it becomes necessary to add liquid metal onto the surface and remove the deposited contaminants. This concept is equally suitable for using any liquid metal. In this case, the heat energy coming from the plasma to the surface is run off 
(a)

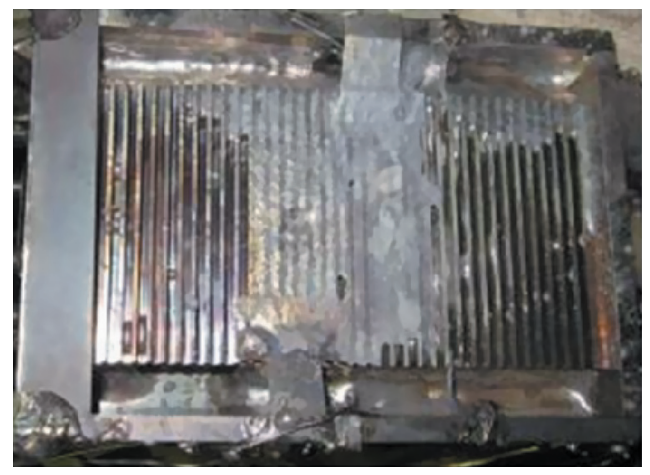

(b)

Flowing Li limiter

in the EAST tokamak

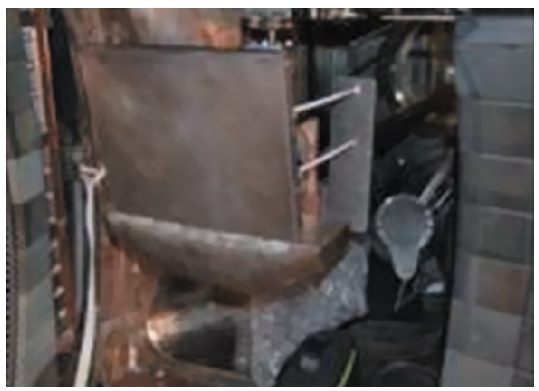

(c)

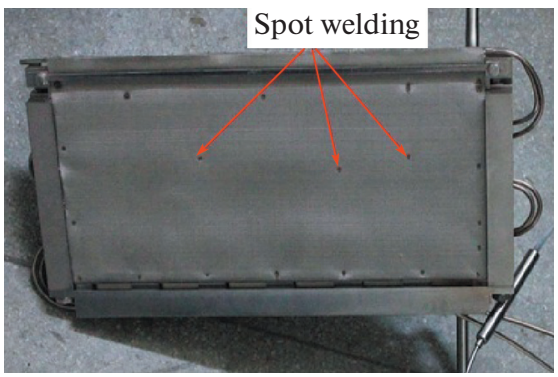

Fig. 4. Flowing lithium limiters used at the EAST tokamak: (a) limiter with LM circulating along channels due to thermoelectric effect, (b) image and (c) schematic of limiter with LM circulation provided by electromagnetic pump and lithium distribution ensured by CPS; coolant is used for heat removal.

(a)

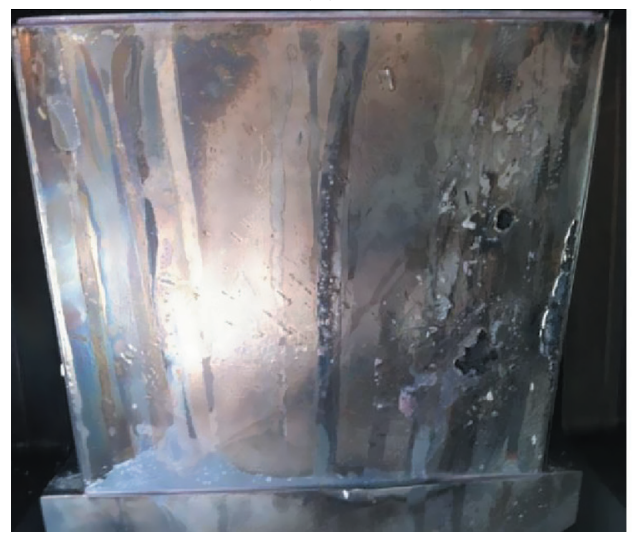

(b)

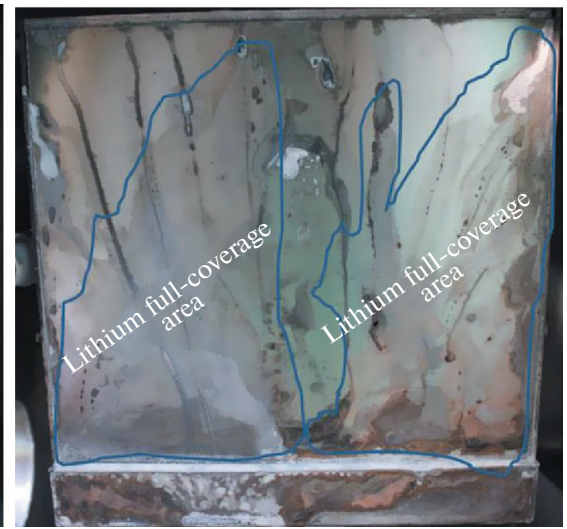

Fig. 5. Surface view of liquid lithium limiter of the EAST tokamak. Lithium velocity of flow is $V_{\mathrm{Li}}=1 \mathrm{~cm} / \mathrm{s}$ (experiments performed in 2016): (a) smooth surface; and (b) capillary grooves perpendicular to the direction of flow [12].

through the ICE structure to the flowing coolant. As the CPS material, it is proposed to use the well-proven porous material based on metal fibers, the properties of which are described in [15].

Separate fields of the LM application in tokamaks are the concepts based on the principle of using the gas/vapor targets [16-18]. In these concepts (see
Figs. 6 and 7), the protection of the reception divertor elements is performed due to the high latent heat of the LM (lithium) vaporization. At first, the incoming plasma energy is spent on the LM evaporation from the surface of the reception plate and then it is redistributed over the large surface of the divertor channel walls during the vapor condensation. This ensures the 


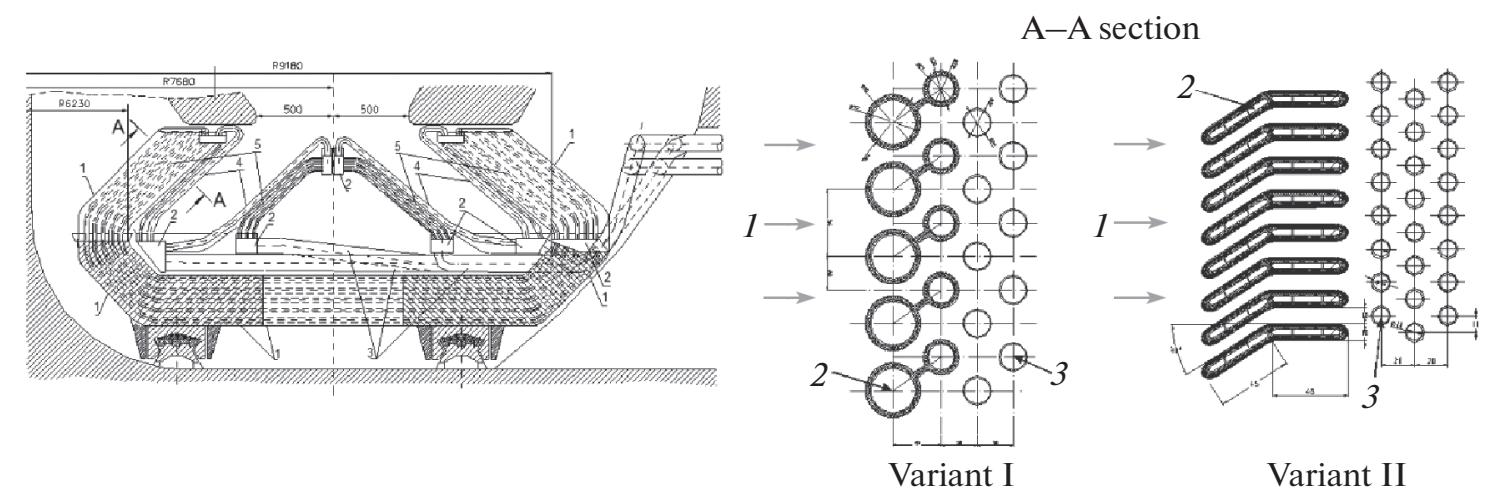

Fig. 6. Schematic of possible design of tokamak reactor liquid metal divertor covered with lithium [16, 17]. (1) Energy flow, (2) channels of lithium evaporation zone, and (3) channels of lithium condensation zone.

(a)

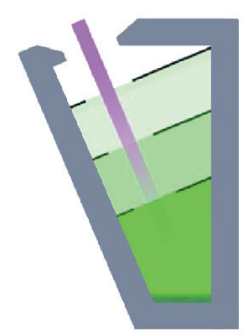

(b) Decimal logarithm of density

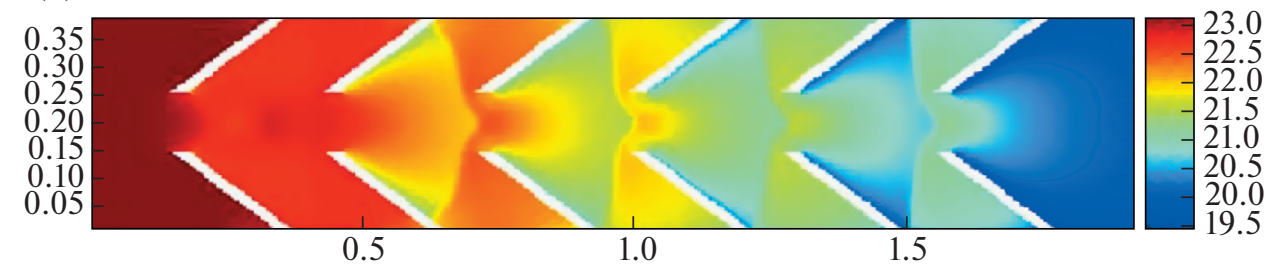

Fig. 7. (a) Schematic of lithium-containing divertor and (b) distribution of lithium vapor flow in divertor channel within the concept of LM divertor of the "vapor box" type for the DEMO reactor ("the box" bottom is on the left) [18].

gentle conditions for the heat dissipation through the divertor channel walls to the coolant. In addition, the evaporated LM creates a dense cloud of LM vapor above the surface of the reception plate, which serves as a "vapor" target. In the volume of such a target, a part of the incoming plasma energy is reradiated. The energy of reradiated photons is redistributed over the surface of the channel walls. Since the channel surface is several times larger than the surface of the reception plate, the heat flux falling onto the walls is reduced by several times. If the appropriate conditions are provided in the divertor, the regime with the detached plasma can arise. The possibility of implementing such a protection mechanism was demonstrated in experiments with the LM targets at the Pilot-PSI facility [19].
The concept of ICE protection was proposed in [20] based on reradiation by lithium atoms (non-coronal radiation) of most of the energy of plasma particles escaping to the SOL. Lithium inflows to the SOL due to evaporation/sputtering from the surface of the lithium-coated limiter installed in the plasma region outside the last closed magnetic surface. Lithium ions flying towards the first wall surface of the tokamak chamber are intercepted by the collectors installed in the shadow of the limiter, which is the lithium source. Thus, the heat fluxes falling onto the ICEs from the plasma decrease and the closed cycle of lithium circulation in the tokamak chamber is organized preventing from lithium uncontrolled accumulation.

The concept of the liquid-metal-coated ICEs for the stationary tokamak reactor of the DEMO type is considered in detail in [21]. 
Table 1. Temperature limit of compatibility of structural materials with LM

\begin{tabular}{l|c|c|c}
\hline \multicolumn{1}{c}{ Structural material } & \multicolumn{3}{|c}{ Temperature limit, ${ }^{\circ} \mathrm{C}$} \\
\cline { 2 - 4 } & $\mathrm{Li}$ & Sn/Sn-Li alloy & $\mathrm{Ga}$ \\
\hline Ferritic/ferritic-martensitic chromium steel & 800 & $<400$ & $<400$ \\
Austenitic Cr-Ni steel & 700 & $<400$ & $<700$ \\
V and V-Cr-Ti alloys & 900 & $<700$ & $<700$ \\
Mo and alloys & 1200 & 1000 & $700-900$ \\
W and alloys & 1500 & 1200 & $>150$ \\
Cu and alloys & $>180$ & $>230$ & \\
\hline
\end{tabular}

In addition to lithium, gallium, tin, and tin-lithium alloy are now actively considered as liquid metals that can be used in the fusion reactor [3-5]. The final LM choice can be made only based on the following selection criteria: the experience of using under the tokamak conditions, the availability of the proven technology for the LM application, the compatibility with the ICE structural materials, the physicochemical properties, and the susceptibility to activation [21-26].

It is believed that the upper temperature limit for the LM applicability is determined by the permissible flux of its evaporated or sputtered atoms into the plasma. For lithium and tin, the limits are $\sim 500$ and $\sim 1000^{\circ} \mathrm{C}$, respectively, but taking into account the redeposition mechanism, it can reach $\sim 700$ and $1250^{\circ} \mathrm{C}$, respectively [26]. For the $\mathrm{Li}-\mathrm{Sn}$ alloy, the pressure of saturated lithium vapors above the melt is more than three orders of magnitude lower than the corresponding vapor pressure for pure $\mathrm{Li}$ [27]. For tin, evaporation is not observed at temperatures less than $1000^{\circ} \mathrm{C}$ [28]. For this reason, the use of $\mathrm{Sn}-\mathrm{Li}$ alloys in the ICEs looks preferable from the point of view of the higher permissible temperature.

The ranges of operating temperatures, determined by the LMs compatibility with the ICE structural materials and CPS [29], are given in Table. 1.

As can be seen, gallium is the most aggressive metal among the proposed LMs, and we exclude it from consideration. The specified temperature limits should be taken into account when designing the ICEs, choosing the structural material and determining the permissible heat flux. For these reasons, lithium can be considered as the most preferred LM. In all the concepts under consideration, the wettability of structural materials with the LMs is the critical aspect. For the selected structural materials, the wetting angles of lithium and tin are $\sim 0^{\circ}$ and $20^{\circ}-30^{\circ}$, respectively. The problem of wetting the structural metals with tin is non-trivial and in this case, the development of wetting technology is absolutely necessary. For the $\mathrm{Li}-\mathrm{Sn}$ alloy, this problem is not so critical, since the presence of lithium results in its higher chemical reactivity with respect to the oxide layers on the surfaces of the solid structural materials. Never- theless, the technology for wetting the ICE structural materials with the $\mathrm{Li}-\mathrm{Sn}$ alloy requires further elaboration.

For safety reasons, the total amount of lithium in the reactor chamber should not exceed a certain limit, which can be determined based on the maximum possible hydrogen pressure in the chamber $(0.2 \mathrm{MPa})$ that can arise as a result of the chemical reaction of the total amount of lithium with water [30]. At the assumed area of the reception plates of $\sim 66 \mathrm{~m}^{2}$, a CPS thickness of $0.5 \mathrm{~mm}$ and a CPS porosity of $40 \%$, the calculated amount of lithium in the divertor of the DEMO-type reactor based on the lithium CPS will be $\sim 13 \mathrm{~L}(\sim 6.5 \mathrm{~kg})$, which meets the safety requirements. This problem does not arise when the $\mathrm{Li}-\mathrm{Sn}$ alloys are used.

Since lithium is an active hydrogen absorber, there arises the problem of trapping and accumulation of radioactive tritium in the tokamak reactor chamber. For DEMO, the limit for the permissible amount of captured tritium should not exceed $1 \mathrm{~kg}$ [30]. However, taking into account that at $600^{\circ} \mathrm{C}$, the equilibrium pressure of the $\mathrm{Li}-\mathrm{H}$ system is $270 \mathrm{~Pa}$, and the maximum pressure in the divertor can be even higher, in order to prevent the formation of lithium tritides or deuterides, it is necessary to organize the lithium recycling in order to reduce the concentration of hydrogen isotopes in the LM solution to the values less than the critical concentration for the formation of these compounds. For the $\mathrm{Li}-\mathrm{Sn}$ alloy, this aspect is not critical and does not require any special measures. Thus, the rate of lithium renewal realized in the divertor will make impossible the formation of lithium hydrides/tritides, and the total amount of trapped tritium in the chamber will be much lower than the maximum permissible value. For $\mathrm{Sn}$ and $\mathrm{Li}-\mathrm{Sn}$ alloys, this aspect is not critical and does not require any special measures.

Comparing the stabilities of the state of aggregation and compositions of the LMs under consideration, we note that pure metals, such as $\mathrm{Li}$ and $\mathrm{Sn}$, are stable, in contrast to the $\mathrm{Li}-\mathrm{Sn}$ alloy. 
For the Li-Sn alloy, a change in the lithium concentration can occur due to its evaporation during the operation of ICEs. This can result in the fact that with time, the alloy located in the high-temperature ICE region becomes depleted in lithium and the lithium flux required for plasma conditioning becomes noticeably reduced. The most critical result of the lithium redistribution is the possible formation of the refractory compounds (intermetallic compounds with a melting point of $\sim 700-800^{\circ} \mathrm{C}$ ) on the surface of the ICE cold zones due to the deposition of lithium and an increase in its concentration on the surface. Among other things, the melting point of the $\mathrm{Li}-\mathrm{Sn}$ alloy is higher than that of pure lithium and tin. For the $(75$ at $\% \mathrm{Sn}+25$ at \% Li) alloy considered as the promising one, the melting point is approximately $350^{\circ} \mathrm{C}$. In a temperature range of $222-350^{\circ} \mathrm{C}$, several phases are present in the melt. In the liquid melt with the low lithium concentration, there is the solid phase $\mathrm{Li}_{2} \mathrm{Sn}_{5}$ enriched in lithium. Thus, the use of the $\mathrm{Li}-\mathrm{Sn}$ alloy as a plasma facing material is in doubt.

Based on the foregoing, pure lithium is the most preferable liquid metal for the implementation of the LM ICE concept for the tokamak reactor.

\section{SELECTION OF CONSTRUCTION MATERIALS FOR LIQUID-METAL INTRACHAMBER ELEMENTS}

We note that under the DEMO conditions, from the point of view of the activation and effect of the radiation damage on the properties of structural materials, the materials such as chromium stainless steels, vanadium alloys, and tungsten alloys are considered acceptable. Copper alloys can be only in very finite use. The analysis should take into account the possible real ICE designs and the availability of technologies for their manufacturing. For example, it is difficult to imagine the real tokamak ICEs entirely consisting of tungsten or its alloys. Tungsten can be successfully used in the form of a fibrous material for the CPS base or ICE protective plates. Thus, chromium steels and vanadium alloys can be considered as the main structural materials for ICEs. From this point of view, the temperature threshold for using lithium or tin in the real ICE design is determined by the lowest threshold among the materials in contact with the LM. In this case, the contact of copper and its alloys with the LMs is unacceptable, at least without using the protective coatings. Thus, the temperature thresholds (see Table 1) for using lithium in the ICEs, which include steel and vanadium elements, are 800 and $900^{\circ} \mathrm{C}$, respectively. For tin, this limit does not exceed 400 and $700^{\circ} \mathrm{C}$ for steel and vanadium structures, respectively. Thus, when lithium is used, the acceptable ICE surface temperature can be considered to be $700^{\circ} \mathrm{C}$ (with allowance for the limitations imposed on the permissible lithium flux into the plasma). For tin, the permissible surface temperature is approximately $1000^{\circ} \mathrm{C}$
Table 2. Limiting heat flux onto the surfaces of ICE structural materials*

\begin{tabular}{l|c}
\multicolumn{1}{c|}{ Material } & Heat flux, $\mathrm{MW} / \mathrm{m}^{2}$ \\
\hline $\begin{array}{l}\text { Ferritic/ferritic-martensitic } \\
\text { chromium steel }\end{array}$ & 3.5 \\
V-Cr-Ti alloy & 9.5 \\
Composite, 67\% tungsten + & 21 \\
33\% ferritic chromium steel & \\
W and alloys & 48 \\
\hline
\end{tabular}

*Wall thickness is $1 \mathrm{~mm}+0.5 \mathrm{~mm}$-thick CPS with lithium, ICE surface temperature is $650^{\circ} \mathrm{C}$.

(the contact with only tungsten is assumed). However, for the areas of the ICE constructions, where the LMs are in contact with steel and vanadium alloy, it is only 400 and $700^{\circ} \mathrm{C}$, respectively.

With allowance for the effect of neutron irradiation (radiation damage is up to $5 \mathrm{dpa} /$ year) on the properties of the divertor structural materials, the permissible temperature ranges of their use in the design of ICEs are as follows [2]: $350-550^{\circ} \mathrm{C}$ for steel of the Eurofer type; $400-700^{\circ} \mathrm{C}$ for the $\mathrm{V}-\mathrm{Cr}-\mathrm{Ti}$ alloy; $200-350^{\circ} \mathrm{C}$ for $\mathrm{Cu}$; and more than $650^{\circ} \mathrm{C}$ for $\mathrm{W}$ alloys. This means that when designing the ICEs, the materials used must be placed in the ICE structure zones with permissible temperatures. Thus, based on the temperature limits of the structural material compatibility with the LMs (Table 1), the thermal properties of the material, and the strength criterion (SDC-IC), it is possible to estimate the maximum permissible heat flux onto the ICE surfaces for the materials under consideration (Table 2).

From the analysis of the data given in Table 2, it follows that only tungsten meets the requirements for the ICE stationary operation at fluxes of $10-$ $20 \mathrm{MW} / \mathrm{m}^{2}$. Therefore, in order to design real ICE structures, it is necessary to develop a new structural material for the ICE reception surface with high strength and thermal physical properties.

A new composite material was proposed that is the three-dimensional porous structure based on tungsten fibers, which is filled with the ferritic stainless steel. The sample of the prototype of such a composite material (67\% tungsten fiber $+33 \%$ pure iron) is shown in Fig. 8. As shown by the calculations, the optimal composition of such a material is (67\% tungsten fiber $+33 \%$ steel) and it has the optimal properties. The expected properties of the composite estimated from the calculations are presented in Table 3.

In addition, the proposed composite material can be quite manufacturable and have good weldability with other ICE components made of steel of the Rusfer (Eurofer) type. To confirm this assumption, it will be necessary to manufacture and research this mate- 


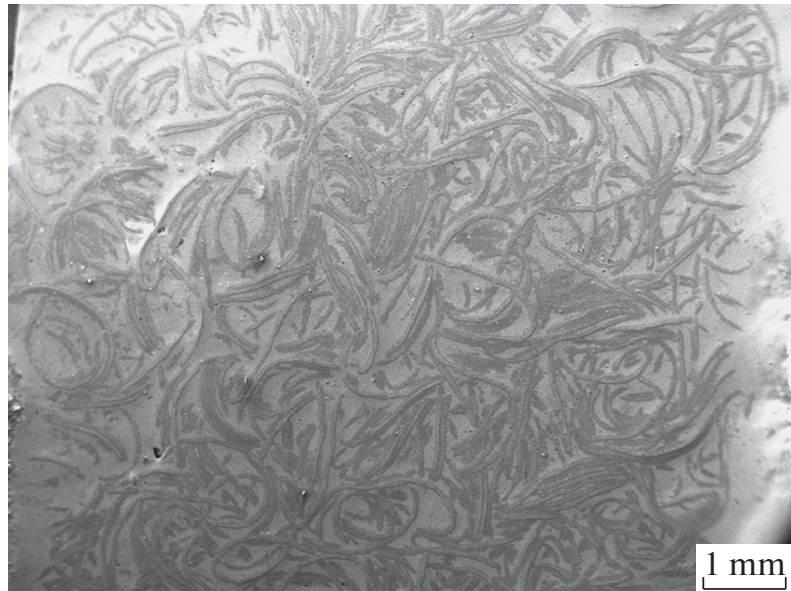

Fig. 8. Surface view of the $67 \% \mathrm{~W}+33 \%$ Fe composite.

rial. The first samples of the model composite material have already been obtained by means of impregnating a porous sample made of tungsten wire with highpurity iron. The research has begun on their mechanical and thermal physical properties. The surface appearance of the resulting composite is shown in Fig. 8.

The choice of the base material for the CPS is a very important aspect of the ICE concept. Fibrous porous materials are the optimal solution in terms of the mechanical properties and resistance to the thermal shock and radiation exposure. Moreover, the nonsintered materials, such as the wire mesh, felt and "metal rubber," have clear advantages in the flexibility, impact resistance and stress relaxation. With allowance for the corrosion resistance and thermal physical properties, it is preferable to use the CPS based on the porous material made from the tungsten fiber.

Typically, the CPS structure consists of two layers. The surface layer determines the CPS capillary properties. The small size of the CPS pores ensures the high capillary pressure and increased LM stability on the ICE surface. For the real CPSs used at tokamaks, the typical pore radius is $10-30 \mu \mathrm{m}$, which corresponds to

Table 3. Design properties of composite material $(67 \%$ tungsten fiber $+33 \%$ steel)

\begin{tabular}{l|c}
\hline \multicolumn{1}{c|}{ Property } & Value \\
\hline Heat conduction, W/(m K) & 91 \\
Yield point, MPa & 1060 \\
Ultimate strength, MPa & 1180 \\
Modulus of elasticity, GPa & 327 \\
Poisson ratio & 0.36 \\
Coefficient of thermal expansion, 1/K & $6.6 \times 10^{-6}$ \\
\hline
\end{tabular}

the pressures $(4-7) \times 10^{4}$ and $(2.5-5) \times 10^{4}$ Pa for tin and lithium, respectively (Fig. 9). Such pores provide for the sufficient LM rise in the capillars to ensure the efficient renewal of the ICE surfaces.

To ensure the CPS functionality under the tokamak conditions, its surface structure should satisfy the following inequality [22]:

$$
P_{\mathrm{C}} \geq \Delta P_{\mathrm{L}}+\Delta P_{\mathrm{G}}+\Delta P_{\mathrm{F}}+\Delta P_{\mathrm{MHD}}
$$

where $P_{\mathrm{C}}$ is the capillary pressure, $\Delta P_{\mathrm{L}}$ is the hydraulic pressure drop, $\Delta P_{\mathrm{G}}$ is the hydrostatic pressure drop, $\Delta P_{\mathrm{F}}$ is the pressure drop on the evaporating surface due to the liquid-vapor phase transition, and $\Delta P_{\mathrm{MHD}}$ is the pressure drop due to the MHD effect in the magnetic field. The components of the inequality can be estimated as follows: $\Delta P_{\mathrm{L}}=\left(8 m \mu L_{\mathrm{CPS}}\right) /\left(S_{\mathrm{CPS}} \varepsilon R_{\mathrm{eff}}^{2} \gamma\right)$, where $m$ is the evaporation rate, $\mu$ is the dynamic viscosity of lithium, $L_{\mathrm{CPS}}$ is the CPS size along the LM flow direction, $S_{\mathrm{CPS}}$ is the CPS cross-sectional area, $\varepsilon$ is the bulk porosity, $R_{\text {eff }}$ is the effective radius of the CPS pores, and $\gamma$ is the lithium density; $\Delta P_{\mathrm{G}}=\gamma g h$, where $g$ is the free fall acceleration, and $h$ is the height above the bottom; the $\Delta P_{\mathrm{F}}$ component can be estimated with good accuracy as half the saturation vapor pressure of lithium $P_{\mathrm{s}}$ at the corresponding surface temperature; and $\Delta P_{\mathrm{MHD}}=B^{2} L_{\mathrm{CPS}} V(1+l / \delta)^{2} \delta^{2} /\left(\rho l^{2}\right)$, where $B$ is the magnetic field, $v$ is the velocity of lithium flow, $\delta$ is the diameter of the CPS wire, $l$ is the size of the CPS cell "just as it is," and $\rho$ is the electrical resistance of lithium. The expression was obtained based on the experimental data on the studies of the MHD effect on the lithium flow in the CPS. Consequently, during the normal discharges, the CPS will operate without being damaged. The CPS will be able to stabilize liquid lithium on its surface during plasma disruption, if the inequality $P_{\mathrm{C}} \geq P_{\mathrm{EM}}$ is satisfied, where $P_{\mathrm{EM}}$ is the pressure pulse induced in liquid lithium by the electromagnetic forces during plasma disruption.

The CPS ability to resist the disruption and transient processes is determined by the following requirements for the CPS structure [31], which were determined experimentally and also calculated. In order the CPS not to be damaged under conditions of the pulsed heat flow of $\sim 100 \mathrm{GW} / \mathrm{m}^{2}$, the radius of the CPS pores should be less than $140 \mu \mathrm{m}$, and the wire diameter should be less than $200 \mu \mathrm{m}$.

Under conditions of the tokamak reactor with a field of $6 \mathrm{~T}$, the total pressure loss in the CPS is estimated to be $10 \mathrm{kPa}$. Consequently, the CPS with a pore size of approximately $10-30 \mu \mathrm{m}$ will operate without damage both in the normal discharges and during the plasma disruptions.

The second (inner) layer should ensure the LM flow in the CPS structure. It is usually ensured by reducing the drop in the hydraulic resistance by means 


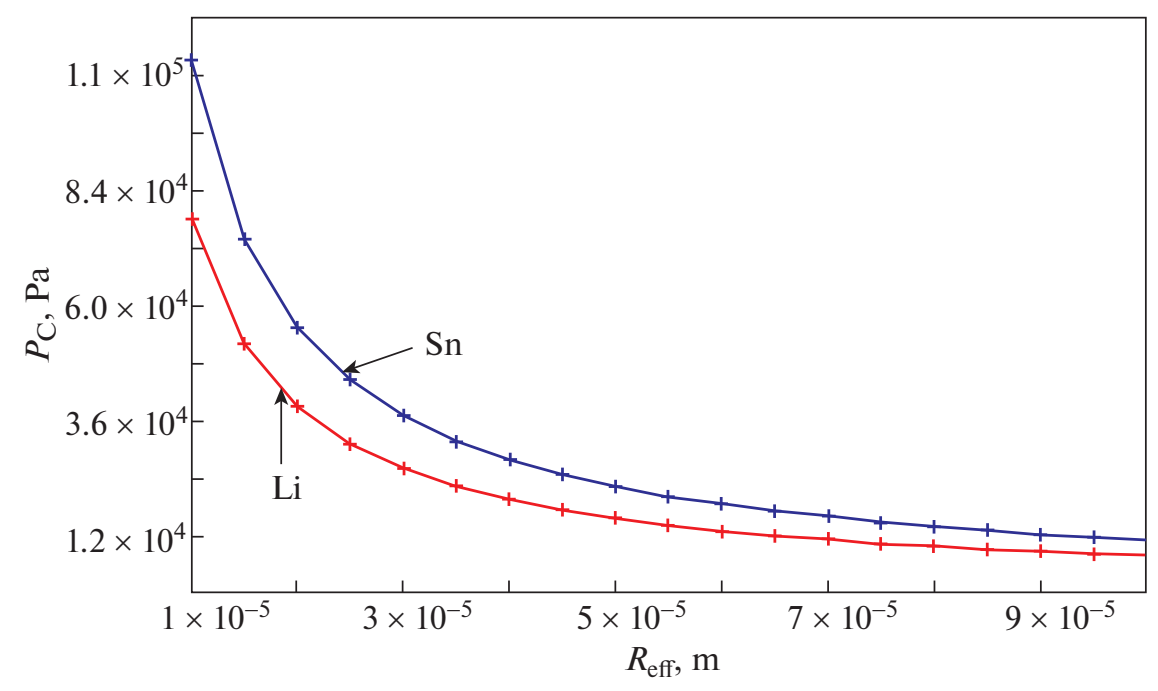

Fig. 9. Capillary pressure $P_{\mathrm{C}}$ as a function of the effective radius $R_{\mathrm{eff}}$ of the pores in the CPS filled with Li and $\mathrm{Sn}$.

of creating the arterial structure in the CPS with effective arterial diameters of $100-200 \mu \mathrm{m}$.

The heat conductions of the porous structures and composite materials has been extensively studied. But, for the concrete CPS structures, the additional experimental research is required. The results from the CPS heat conduction calculations and data on lithium and tungsten are presented in Table 4.

The capillary effect (capillary pressure $P_{\mathrm{C}}$ ) is highly dependent on the wetting angle. The low chemical activity of tin causes the problem of how to ensure the reliable wetting of the CPS base materials. To ensure this, the wetting angle should be $\Theta>\pi / 2$ and therefore, the $P_{\mathrm{C}}$ pressure will be low. For tin, the lowest wetting angle equal to $\Theta \sim \pi / 6$ can be reached only after cleaning the hard metal surface using the specially developed technique. In addition, the high specific density of tin results in its low capillary rise in the CPS, which is a limiting factor for the self-renewal of the ICE surfaces. Therefore, in order to ensure the self-renewal of the ICE surfaces and filling the CPS with tin, it is necessary to develop the special wetting procedure.

Table 4. Heat conduction of $\mathrm{Li}, \mathrm{W}$, and $\mathrm{W}+\mathrm{Li} \mathrm{CPS}$, $\mathrm{W} /(\mathrm{m} \mathrm{K})$

\begin{tabular}{c|c|c|c}
\hline $\begin{array}{c}\text { Tempera- } \\
\text { ture, K }\end{array}$ & $\begin{array}{c}\text { Heat } \\
\text { conduction } \\
\text { of Li }\end{array}$ & $\begin{array}{c}\text { Heat } \\
\text { conduction } \\
\text { of W }\end{array}$ & $\begin{array}{c}\text { Mean heat } \\
\text { conduction } \\
\text { of CPS }\end{array}$ \\
\hline 700 & 50.6 & 130.2 & 48.6 \\
900 & 55.9 & 120.2 & 49.9 \\
1000 & 58.2 & 116.6 & 50.6 \\
1200 & 62.1 & 113.5 & 52.3 \\
\hline
\end{tabular}

For lithium, there is no problem with wetting the hard metal surfaces. For lithium, the wetting angle for steel, W and other metals is close to zero immediately after the first wetting procedure without taking special measures for preliminary surface cleaning. Currently, the ICE design options are being tested with the tungsten CPS manufactured using the 3D printing [32].

\section{CHOICE OF HEAT-TRANSFER AGENT AND COOLING SYSTEM}

An important aspect of the concept is the choice of a heat-transfer agent and design of the heat removal system. The design of the ICEs should ensure the balanced levels of the surface temperature $T_{\text {surf }}$ of the corresponding $\mathrm{LM}$ and the temperature $T_{\text {wall }}$ of the inner wall of the cooling channel. It should be borne in mind that the $T_{\text {wall }}$ temperature has a strong effect on the required coolant pressure (for liquid heat-transfer agents), which prevents from the occurrence of the heat-transfer crisis.

For the concept with the slowly flowing thin LM film, heat is usually removed through the ICE structure to the coolant flowing in the channels of the cooling system. For the fusion reactor, such coolants as water, liquid metal (lithium), and gas (argon) are usually considered as heat-transfer agents [1]. At present, it has been proposed to use fine water mist spray carried by the gas flow as a coolant $[33,34]$. For a singlephase coolant (lithium, water, helium), the convective heat transport is determinant, and the heat conduction of coolant is of primary importance. At the wall temperature $T_{\text {wall }}>100^{\circ} \mathrm{C}$, evaporation is the main heat transport process for the gas-water mixture. This process is most efficient. When comparing the operating parameters and heat transport coefficients (Table 5) of different heat-transfer agents, it can be 
Table 5. Basic parameters and heat-transfer coefficients of heat-transfer agents

\begin{tabular}{l|c|c|c|c}
\hline Heat-transfer agent & Pressure, $\mathrm{MPa}$ & Flow rate, $\mathrm{m} \mathrm{s}^{-1}$ & Temperature, ${ }^{\circ} \mathrm{C}$ & $\begin{array}{c}\text { Heat-transfer coefficient, } \\
\mathrm{kW} \mathrm{m}^{-2} \mathrm{~K}^{-1}\end{array}$ \\
\hline $\begin{array}{l}\text { Liquid lithium } \\
\text { Water }\end{array}$ & 0.01 & 1 & 200 & 44 \\
Gas (helium) & 5 & 10 & 200 & 52 (curled flow), \\
25 (normal flow) \\
Gas-water mixture
\end{tabular}

seen that the efficiency of heat removal, the pressure and flow rate of the gas-water mixture are advantageous. For example, when the temperature of the cooled wall rises from 100 to $350^{\circ} \mathrm{C}$, the water pressure should increase in the range of 1-160 atm. For the gas-water mixture, a pressure of 2-4 atm is acceptable at all temperatures $T_{\text {wall }}>100^{\circ} \mathrm{C}$. For lithium used as a coolant, the pressure less than $0.1 \mathrm{~atm}$ is sufficient.

Thus, only liquid lithium and gas-water mixture can be considered as suitable heat-transfer agents that provide for the permissible ICE surface temperatures at the required heat fluxes of up to $20 \mathrm{MW} / \mathrm{m}^{2}$. Other coolants must have too high pressures and flow rates, which results in the large wall thicknesses and the ICE surface temperatures exceeding the limits.

For liquid lithium, a critical issue is the high flow resistance in the cooling system due to the MHD forces. But it is well compatible with the ICEs containing lithium and tin.

Water is considered as an acceptable heat-transfer agent for the tin-containing ICEs when the temperature of the cooling channel wall is below $200^{\circ} \mathrm{C}$. We note that in vacuum or in the noble gas atmosphere, the reaction of lithium with water does not lead to explosion, but only to release of hydrogen. Water leakage would not result in the catastrophic consequences, if the amount of lithium in the tokamak reactor chamber does not exceed the specified limit. At a heat flow of $10 \mathrm{MW} / \mathrm{m}^{2}$, the flow rates of water and gas used for cooling the ICEs are $\sim 4 \mathrm{~L} \mathrm{~m}^{-2} \mathrm{~s}^{-1}$ and $1.7 \mathrm{~m}^{3} \mathrm{~s}^{-1}$, respectively. From the point of view of the consequences of the ingress of water into the reactor vacuum chamber with the lithium-containing ICEs, such a coolant is less dangerous. Thus, the gas-water mixture can be considered as the optimal coolant for the LM-containing ICEs.

\section{CHOICE OF BASIC CONCEPT OF LITHIUM FIRST WALL FOR TRT}

The concept of the lithium first wall of the TRT tokamak is determined by the design operating parameters of its elements. It is assumed that the main part of the first wall surface is subjected to the stationary (with duration of more than $100 \mathrm{~s}$ ) heat load of $0.1-$ $0.2 \mathrm{MW} / \mathrm{m}^{2}$. In addition, a short (with duration of $<1 \mathrm{~s})$ effect of plasma onto the wall surface is possible during the transient processes. Heat fluxes of 1$5 \mathrm{MW} / \mathrm{m}^{2}$ are expected in the upper and lower parts of the first chamber wall when the discharge is ignited (start-limiter regime). In the region adjacent to the divertor inlet, we expect that the vertical displacement of the plasma column, being the source of the high heat fluxes, will act on the first wall. With allowance for the above conditions and results of analysis, we propose the following types of the first wall elements in order to protect the plasma from the ingress of the undesirable heavy impurities and to keep the ICE structure integrity.

\subsection{ITER-like ICEs of the First Wall}

We assume that the main part of the first wall will be designed from the panels based on the ITER-like elements with active cooling by the water flow. The base element of the panel consists of a cooling tube made from the copper alloy and coated with beryllium plates. At a heat flux of $0.1-0.2 \mathrm{MW} / \mathrm{m}^{2}$ onto the surface, a temperature of $<180^{\circ} \mathrm{C}$ is expected on the panel surfaces. To prevent the copper tubes from damage during the possible deposition of lithium on their surface, it is proposed to apply a thin protective coating made from the material, which is compatible with lithium at the temperatures specified above.

The surface conditioning of such ICEs can be performed by means of periodically applying a thin lithium layer. Lithium can be deposited both using the forced heating evaporators and lithium emitters introduced into the tokamak edge plasma. The use of lithium conditioning results in a decrease in the flow of impurities entering the plasma and considerably improves the parameters of the plasma discharge.

\subsection{Lithium Evaporator}

In essence, the evaporator is a device, the inner volume of which contains a small amount of lithium, sufficient for the device operation during the TRT toka- 


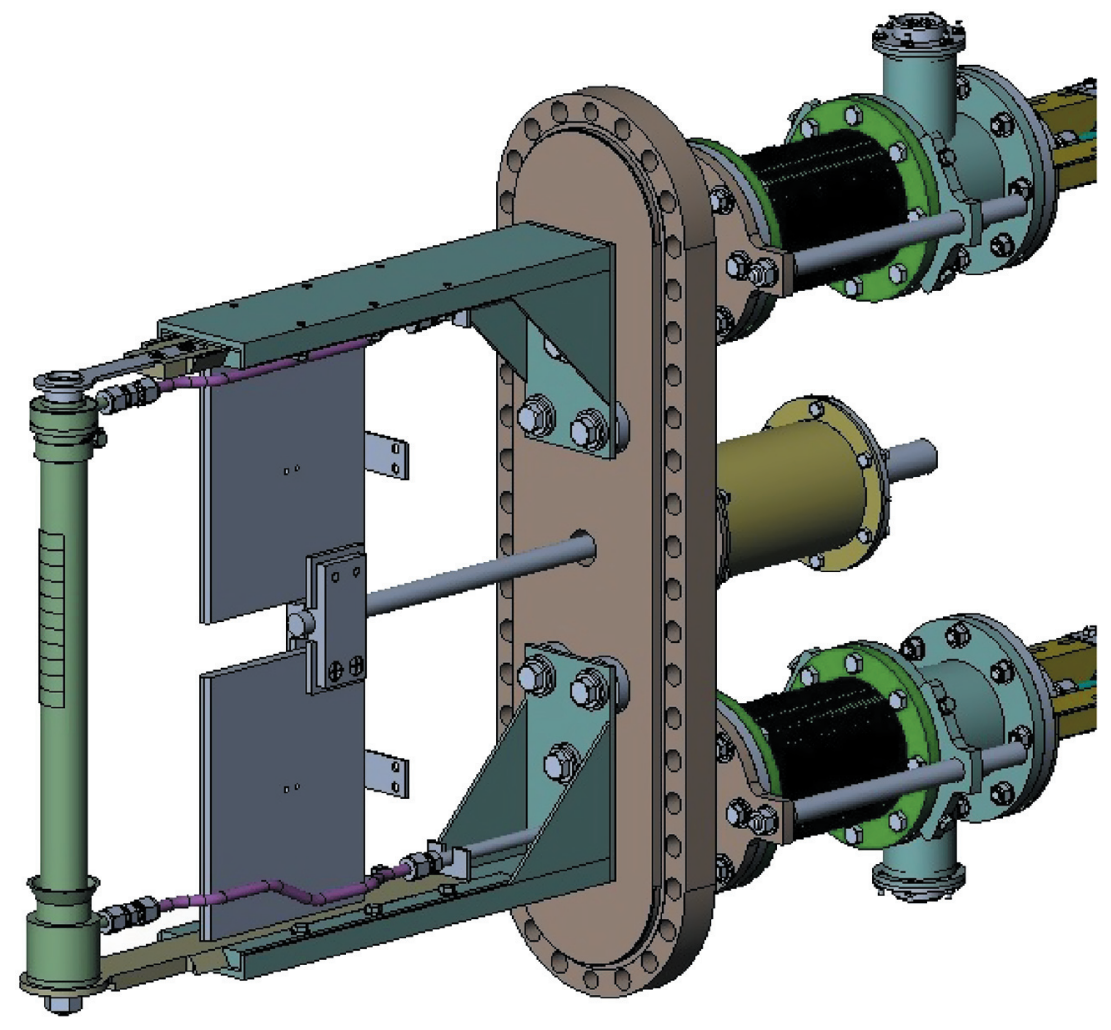

Fig. 10. Prototype of lithium emitter for testing at the T-11M tokamak.

mak campaign. The device should be equipped with the electrical heater and thermocouple to control the vaporized lithium flow. In addition, the evaporator is equipped with the manipulator for introducing it into the chamber and positioning, as well as the device for directing the vapor flow. With the help of such an evaporator, in the intervals between the facility shots, it will be possible to apply the lithium layer on the preselected part of the first wall surface. To ensure the uniformity of applying lithium coating over the entire inner chamber surface, several such devices are required. Such devices have been successfully used for lithium deposition on the inner surface of the TJ-II stellarator chamber and divertor of the NSTX tokamak [3].

\subsection{Litrhium Emitter}

The lithium emitter designed in the form of an uncooled limiter introduced into the edge plasma can ensure the required lithium flux due to its sputtering and evaporation from the surface heated by the plasma flow. The intensity of lithium injection can be regulated by changing the depth of the limiter insertion (distance to the last closed magnetic surface) using the manipulator.
This approach made it possible to almost exclude the inflow of heavy impurities into the plasma column. A prototype of such a device was designed, manufactured (Fig. 10) and successfully used at the T-11M, T10, and FTU tokamaks and the TJ-II stellarator [35]. The limiter surface is covered with a capillary porous structure (CPS) impregnated with lithium. This makes it possible to stabilize liquid lithium on the emitter surface when it is exposed to the electromagnetic forces and prevent from lithium splashing. In addition, the CPS allows designing the devices with different shapes and orientations in space. Lithium can be supplied to the emitter both from the built-in container and from the outside of the chamber without breaking vacuum.

\subsection{Start-Limiter}

In the initial stage of the plasma discharge formation, the use of a special start-limiter will protect the first-wall elements from the action of heat fluxes of the order of $5 \mathrm{MW} / \mathrm{m}^{2}$. These limiters can be installed at the first wall top and bottom. The design of such a limiter should include both the cooling system capable of maintaining the lithium surface temperature at a level not higher than $500-600^{\circ} \mathrm{C}$ in order to limit the lithium atom flows into the plasma, and the lithium feeding system. 
(a)

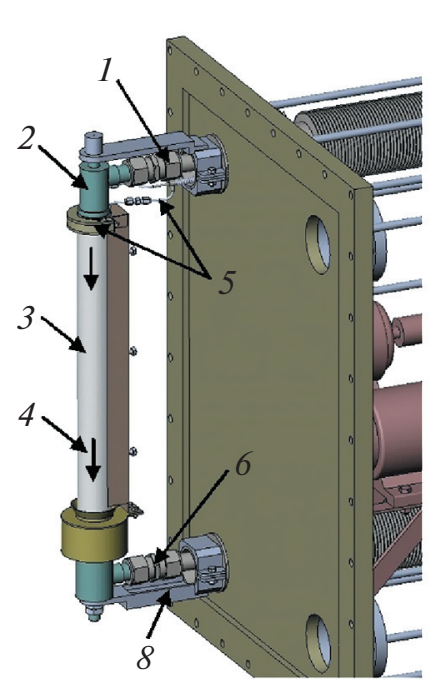

(b)

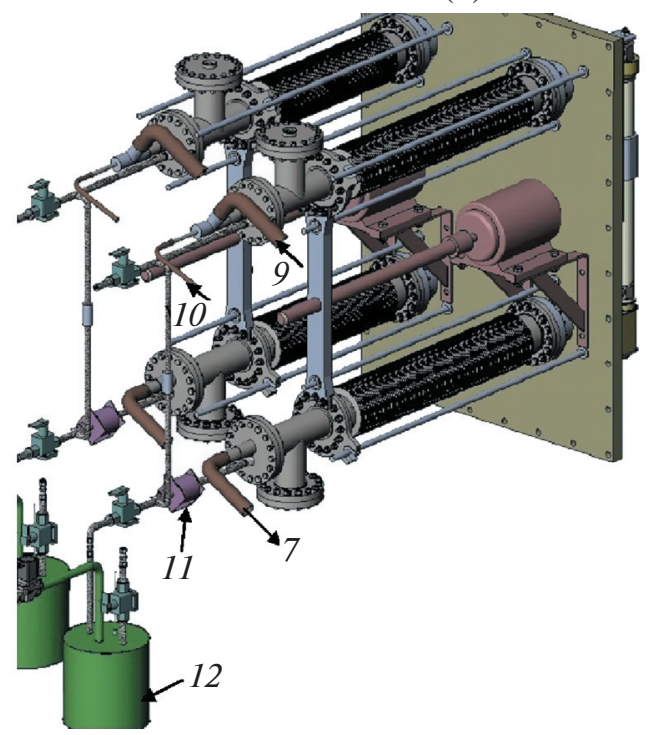

Fig. 11. Schematic of liquid-metal lithium limiter of the T-15MD tokamak: (a) intra-chamber element (ICE) and (b) external lithium supply system and cooling system: (1) supply of gas/water to ICE; (2) sprayer; (3) CPS; (4) lithium flow; (5) supply of lithium to ICE; $(6,7)$ removal of coolant from ICE; $(8)$ removal of lithium from ICE; (9) gas supply to the main pipeline; (10) water supply to the main pipeline; (11) electromagnetic pump; and (12) container with lithium.
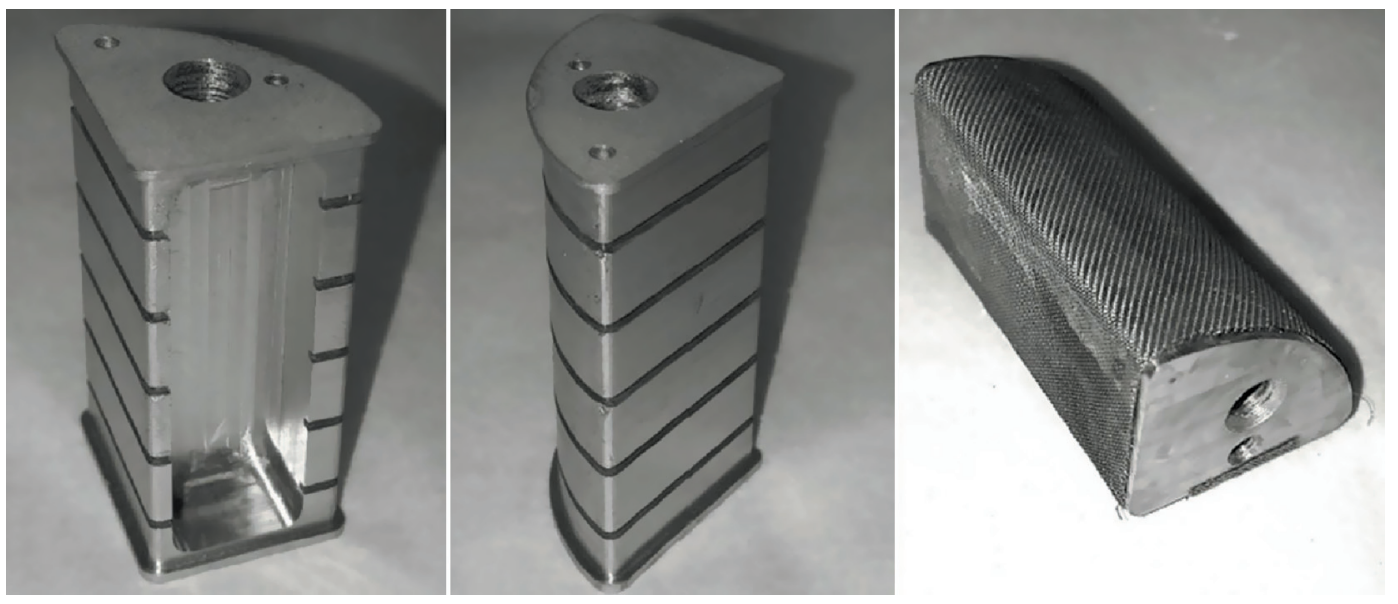

Fig. 12. Images of CPS-based divertor modular unit.

The prototype of such a limiter can be the stationary CPS-based lithium limiter developed for the T-15MD tokamak [21], which is the embodiment of the ground ideas of the ICE concept for the stationary tokamak reactor (Fig. 11).

The limiter is equipped with a system for its displacement relative to the tokamak plasma and is designed for the stationary operation at a thermal load of $10 \mathrm{MW} / \mathrm{m}^{2}$. Such a limiter can work jointly with a similar limiter, acting alternately as the lithium emitter or collector, thereby providing for the closed cycle of lithium circulation in the tokamak chamber, which prevents from the accumulation of lithium on the tokamak walls during its long operation. The gas-water mixture is used as a coolant in the heat removal system. The limiter can be supplied with lithium (for lithium replenishing and ensuring the surface cleaning) using the external electromagnetic pump.

The ICE concept under consideration was approved when testing a series of prototypes of the stationary operating ICEs with LM coating for the T-11M, FTU, and KTM tokamaks [35-39]. The 


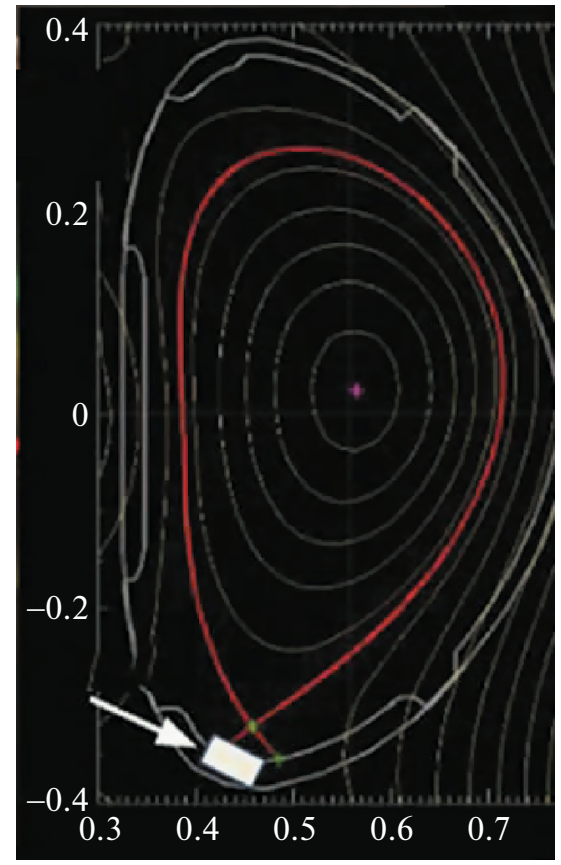

Fig. 13. Arrangement of divertor modular unit in the KOMPASS tokamak (poloidal section of the tokamak plasma column); the arrow indicates position of divertor modular unit.

manufactured prototypes can ensure the ICEs operation in the temperature range of $200-550^{\circ} \mathrm{C}$ at a stationary heat flux of up to $10 \mathrm{MW} / \mathrm{m}^{2}$.

To justify the planned project of the liquid-metal divertor of the KOMPASS-UPGRADE tokamak, a series of experiments was carried out with the divertor targets based on the CPSs filled with Li and LiSn alloy $[40,41]$. Under the conditions of the KOMPASS tokamak (the H-mode with ELMs), the permissible power falling onto the divertor based on the liquid-metalfilled CPS and the behavior of liquid metals under the conditions of the divertor were estimated for the first time. The special divertor modular units $(25 \times 45 \mathrm{~mm})$ were installed in the open divertor of the KOMPASS tokamak in the region of the inner intersection with the separatrix. They were based on the molybdenum CPSs with a pore radius of $75 \mu \mathrm{m}$ and filled with lithium and $\mathrm{Li}-\mathrm{Sn}$ alloy $(73 \% \mathrm{Sn})$. The view of such a modular unit and its arrangement in the divertor are shown in Figs. 12 and 13, respectively. For both variants of the modular units, the CPSs were not damaged and their ability to absorb heat was not violated at the steady-state normal heat flux onto their surfaces of up to $12 \mathrm{MW} / \mathrm{m}^{2}$ and at the local peak energy load of $\sim 15 \mathrm{~kJ} / \mathrm{m}^{2}$. The ejection of liquid metal droplets from the CPS surface was not observed.

Only with an increase in the heat flux to 16$18 \mathrm{MW} / \mathrm{m}^{2}$, for the modular unit with the lithiumfilled CPS, the drying and melting of the CPS surface layer was observed, which was associated with the loss of thermal and hydraulic contact of the surface layer with the base due to its thermal expansion. This effect is a distinctive feature of the CPS structure used, and not a fundamental disadvantage. This defect did not affect the further functionality of the modular unit. The surface temperature of the lithium-filled modular unit reached $450^{\circ} \mathrm{C}$. Exposure to ELMs resulted in an increase in the surface temperature by $40-45^{\circ} \mathrm{C}$. The glow of neutral lithium was observed around the modular unit in the 60-mm-diameter area. In this case, the effect of shielding the modular unit surface by a cloud of lithium vapor was very weak. The estimated fraction of the reradiated heat flux did not exceed $0.1-$ $0.2 \mathrm{MW} / \mathrm{m}^{2}$, which is obviously associated with the low vapor pressure at the observed temperature. The propagation of singly (green) and doubly (blue) ionized lithium in the tokamak chamber is shown in Fig. 14.

At heat fluxes of up to $12 \mathrm{MW} / \mathrm{m}^{2}$, no tin impurity inflow to the discharge was observed. The modular unit surface temperature reached $950^{\circ} \mathrm{C}$. The analysis of two 14-sample-sets installed along the tokamak chamber shows that the considerable amount of lithium is found in the \pm 40 -cm-vicinity of the modular unit. Thus, it is shown that only lithium inflows to the
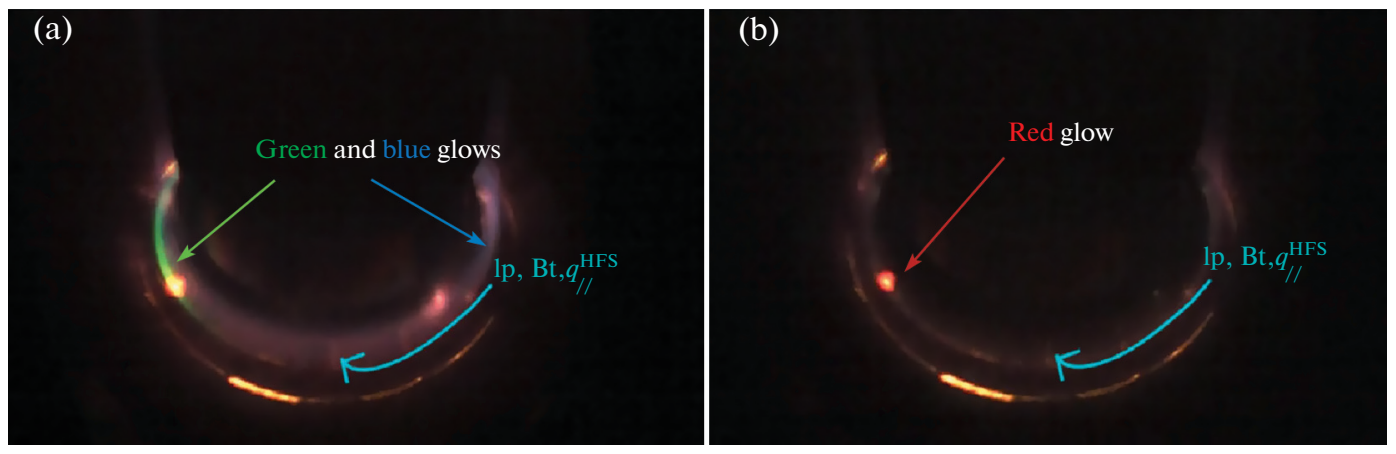

Fig. 14. Lithium dynamics during discharge: (a) during ELMs and (b) between ELMs. 
discharge from the $\mathrm{Li}-\mathrm{Sn}$ alloy. As in the previous case, the shielding by lithium vapor made no noticeable contribution due to the relatively low pressure of lithium vapor at the observed temperature. The introduction of both types of modular units into the tokamak plasma caused no changes in the plasma discharge behavior.

In [42], as an alternative solution to the problem of the divertor element resistances to radiation damage at heat fluxes of up to $20 \mathrm{MW} / \mathrm{m}^{2}$, the concept was considered of the liquid-metal divertor for the stationary EU-DEMO tokamak based on the CPSs filled with liquid tin. Constructive solutions are proposed based on the experience of using liquid-metal limiters at the FTU tokamak, the design of these limiters being previously developed at the Krasnaya Zvezda Corporation.

The approaches used can be implemented to create the reception elements of the first wall and divertor of the TRT tokamak.

\section{CONCLUSIONS}

The analysis performed showed that the concept, involving the CPS-based stabilization of the liquid metal surface, has considerable advantages and should be considered as the basic concept of the TRT lithium first wall. Practical experience in creating and testing the lithium-coated ICEs makes it possible to solve a number of critical issues when developing the appropriate ICE constructions that meet the requirements for the long-term operation under the tokamak reactor conditions. The lithium-filled CPSs provide protection and renewal of the ICE surfaces under the regular discharge conditions, as well as during disruptions and development of different kinds of instabilities.

The first wall elements exposed to the heat fluxes of up to $1 \mathrm{MW} / \mathrm{m}^{2}$ can be designed based on the construction of the water-cooled elements designed for ITER. In this case, their modification should ensure the compatibility of the main structural materials with the deposited lithium. In order to improve the plasma discharge parameters, the first-wall conditioning can be performed using the evaporators and/or emitters for lithium deposition.

In the initial stage of discharge ignition and in the stage of its quenching, the protection of the first wall can be performed using the cooled protective limiters. To ensure the steady-state operation, the design of such limiters should be based on using the lithiumfilled CPS and the systems for cooling, lithium feeding and its removal from the chamber. Choosing appropriately the construction materials, cooling system and coolant, it is possible to ensure the stationary operating regime at heat fluxes of $10 \mathrm{MW} / \mathrm{m}^{2}$ or higher. On the basis of this approach, the reception elements of the divertor can also be designed.

\section{FUNDING}

The work was supported by the State Atomic Energy Corporation ROSATOM under the State Assignment no. 313/1671-D dated September 5, 2019.

\section{OPEN ACCESS}

This article is licensed under a Creative Commons Attribution 4.0 International License, which permits use, sharing, adaptation, distribution and reproduction in any medium or format, as long as you give appropriate credit to the original author(s) and the source, provide a link to the Creative Commons license, and indicate if changes were made. The images or other third party material in this article are included in the article's Creative Commons license, unless indicated otherwise in a credit line to the material. If material is not included in the article's Creative Commons license and your intended use is not permitted by statutory regulation or exceeds the permitted use, you will need to obtain permission directly from the copyright holder. To view a copy of this license, visit http://creativecommons.org/licenses/by/4.0/.

\section{REFERENCES}

1. G. Federici, W. Biel, M. R. Gilbert, R. Kemp, N. Taylor, and R. Wenninger, Nucl. Fusion 57, 092002 (2017). https://doi.org/10.1088/1741-4326/57/9/092002

2. D. Stork, P. Agostini, J.-L. Boutard, D. Buckthorpe, E. Diegele, S. Dudarev, C. English, G. Federici, M. R. Gilbert, S. Gonzalez, A. Ibarra, C. Linsmeier, A. L. Puma, G. Marbach, P. F. Morris, et al., J. Nucl. Mater. 455, 277 (2014).

https://doi.org/10.1016/j.jnucmat.2014.06.014

3. R. E. Nygren and F. L. Tabarés, Nucl. Mater. Energy 9 , $6(2016)$. https://doi.org/10.1016/j.nme.2016.08.008

4. F. Tabarés, E. Oyarzabal, A. B. Martin-Rojo, D. Tafalla, A. de Castro and A. Soleto, Nucl. Fusion 57, 016029 (2017). https://doi.org/10.1088/0029-5515/57/1/016029

5. M. A. Jaworski, A. Brooks, R. Kaita, J. Menard, M. Ono, K. Tresemer, N. Lopes-Cardozo, P. Rindt, and K. Tresemer, Fusion Eng. Des. 112, 93 (2016).

6. S. V. Mirnov, E. A. Azizov, A. Alekseev, V. B. Lazarev, R. R. Khayrutdinov, I. E. Lyublinski, A. V. Vertkov, and V. V. Vershkov, Nucl. Fusion 51, 073044 (2011). https://doi.org/10.1088/0029-5515/51/7/073044

7. I. E. Lyublinski, A. V. Vertkov, and V. A. Evtikhin, Plasma Devices Oper. 17, 42 (2009).

8. I. E. Lyublinski, A. V. Vertkov, S. V. Mirnov, and V. B. Lazarev, J. Nucl. Mater. 463, 1156 (2015). https://doi.org/10.1016/j.jnucmat.2014.12.017

9. A. V. Krasilnikov, S. V. Konovalov, E. N. Bondarchuk, I. V. Mazul, I. Yu. Rodin, A. B. Mineev, E. G. Kuzmin, A. A. Kavin, D. A. Karpov, V. M. Leonov, R. R. Khayrutdinov, A. S. Kukushkin, D. V. Portnov, A. A. Ivanov, Yu. I. Belchenko, et al., Plasma Phys. Rep. 47, 1092 (2021). 
10. J. C. Yang, T. Y. Qi, B. Q. Liu, and M. J. Ni, in Proceedings of the 5th International Symposium on Liquid Metals Application for Fusion, Moscow, 2017, Book of Abstracts, p. 57.

http://plasma.mephi.ru/ru/uploads/files/conferences/2017_ISLA/ISLA2017_programme.pdf.

11. J. Hu, G. Z. Zuo, Z. Sun, W. Xu, R. Maingi, Q. X. Yang, M. Huang, Y. Chen, X. L. Yuan, X. C. Meng, J. G. Li, A. Diallo, R. Lunsford, D. Mansfield, T. Osborne, et al., in Proceedings of the 5th International Symposium on Liquid Metals Application for Fusion, Moscow, 2017, Book of Abstracts, p. 20.

http://plasma.mephi.ru/ru/uploads/files/conferences/2017_ISLA/ISLA2017_programme.pdf.

12. J. S. Hu, G. Zuo, J. Ren, Y. Qingxi, Z. Chen, H. Xu, L. E. Zakharov, R. Maingi, C. Gentile, X. C. Meng, Z. Sun, W. Xu, Y. Chen, D. Fan, N. O. Yan, et al., Nucl. Fusion 56, 046011 (2016). https://doi.org/10.1088/0029-5515/56/4/046011

13. V. A. Evtikhin, I. E. Lyublinski, and A. V. Vertkov, J. Adv, Mater. 2, 650 (1995).

14. M. Yu. Zharkov, A. V. Vertkov, I. E. Lyublinskii, G. E. Notkin, S. A. Grashin, and V. A. Vershkov, in XXIV Conference on Plasma-Surface Interaction, Ed. by Yu. M. Gasparyan, D. N. Sinelnikov, and D. G. Bulgadaryan (National Research Nuclear University MEPhI, Moscow, 2021), p. 67.

http://plasma.mephi.ru/ru/uploads/files/conferences/PSI_PSI_2021.pdf.

15. I. E. Lyublinski and A. V. Vertkov, Fusion Eng. Des. 85, 924 (2010). https://doi.org/10.1016/j.fusengdes.2010.08.036

16. V. A. Evtikhin, I. E. Lyublinski, A. V. Vertkov, S. V. Mirnov, V. B. Lazarev, N. P. Petrova, S. M. Sotnikov, A. P. Chernobai, B. I. Khripunov, V. B. Petrov, D. Yu. Prokhorov, and V. M. Korzhavin, Plasma Phys. Control. Fusion 44, 955 (2002).

17. L. G. Golubchikov, V. A. Evtikhin, I. E. Lyublinski, V. I. Pistunovich, I. N. Potapov, and A. N. Chumanov, J. Nucl. Mater. 233-237, 667 (1996).

18. R. Golston, R. Myers, and J. Shwartz, Phys. Scr. T167, 014017 (2016).

19. T. Morgan, P. Rindt, G. G. van Eden, V. Kvon, M. A. Jaworksi and N. J. Lopes Cardozo, Plasma Phys. Control. Fusion 60, 014025 (2018). https://doi.org/10.1088/1361-6587/aa86cd

20. S. V. Mirnov, A. M. Belov, N. T. Djigailo, A. S. Dzhurik, S. I. Kravchuk, V. B. Lazarev, I. E. Lyublinski, A. V. Vertkov, M. Yu. Zharkov, and A. Shcherbak, Nucl. Fusion 55, 123015 (2015). https://doi.org/10.1088/0029-5515/55/12/123015

21. A. V. Vertkov, I. E. Lyublinski, M. Yu. Zharkov, A. V. Berlov, S. V. Mirnov, A. T. Komov, A. N. Varava, A. V. Zakharenkov, G. Mazzitelli, and M. Iafrati, in Proceedings of the 27th IAEA Fusion Energy Conference, Ahmedabad, 2018, Paper EX/P1-12, p. 209. https://nucleus.iaea.org/sites/fusionportal/Shared\%20Documents/FEC\%202018/FEC2018_ConfMat_Online.pdf.

22. I. E. Lyublinski, V. A. Evtikhin, and A. V. Vertkov, Plasma Devices Oper. 17, 265 (2009).
23. I. E. Lyublinski, A. V. Vertkov, M. Yu. Zharkov, V. V. Semenov, E. A. Azizov, V. B. Lazarev, and S. V. Mirnov, Fusion Eng. Des. 89, 996 (2014).

https://doi.org/10.1016/j.fusengdes.2014.03.073

24. I. E. Lyublinski, A. V. Vertkov, M. Yu. Zharkov, O. N. Sevryukov, P. S. Dzhumaev, V. A. Shumskiy, and A. A. Ivannikov, J. Phys.: Conf. Ser. 748, 012014 (2016).

25. I. E. Lyublinski, A. V. Vertkov, and V. V. Semenov, Phys. At. Nucl. 79, 1163 (2016).

26. T. Morgan, A. V. Vertkov, K. Bystrov, I. E. Lyublinski, J. W. Genuit, and G. Mazzitelli, Nucl. Mater. Energy 12, 210 (2017). https://doi.org/10.1016/j.nme.2017.01.017

27. S. Sharafat and N. Ghoniem, Report UCLA-UCMEP-00-31 (University of California, Los Angeles, 2000). http://www.fusion.ucla.edu/APEX/pdfs/SnLi_Properties_1025.pdf.

28. R. A. Anderl, D. D. Jenson, and G. F. Kessinger, J. Nucl. Mater. 307, 739 (2002). https://doi.org/10.1016/S0022-3115(02)00975-3

29. I. E. Lyublinskii, A. V. Vertkov, and V. A. Evtikhin, Vopr. At. Nauki Tekh., Ser.: Termoyad. Sint. 30 (4), 13 (2007).

30. R. P. Wenninger, M. Bernert, T. Eich, E. Fable, G. Federici, A. Kallenbach, A. Loarte, C. Lowry, D. McDonald, R. Neu, T. Putterich, P. Schneider, B. Sieglin, G. Strohmayer, F. Reimold, and M. Wischmeier, Nucl. Fusion 54, 114003 (2014).

https://iopscience.iop.org/article/10.1088/00295515/54/11/114003/meta.

31. A. V. Vertkov, I. E. Lyublinski, M. Yu. Zharkov, S. V. Mirnov, V. V. Vershkov, G. Mazzitelli, M. Iafrati, F. Tabares, and I. Tazhibayeva, in Proceedings of the 5th International Symposium on Liquid Metals Application for Fusion, Moscow, 2017, Book of Abstracts, p. 56. http://plasma.mephi.ru/ru/uploads/files/conferences/2017_ISLA/ISLA2017_programme.pdf.

32. P. Rindt, S. Korving, T. Morgan, and N. L. Cardozo, Nucl. Fusion, 2021 (in press).

33. A. V. Vertkov, I. E. Lyublinski, M. Yu. Zharkov, G. Mazzitelli, M. L. Apicella, and M. Iafrati, Fusion Eng. Des. 117, 130 (2017). https://doi.org/10.1016/j.fusengdes.2017.01.041

34. A. V. Vertkov, A. T. Komov, I. E. Lyublinskii, S. V. Mirnov, A. N. Varava, A. V. Dedov, A. V. Zakharenkov, and P. G. Frik, Vopr. At. Nauki Tekh., Ser.: Termoyad. Sint. 41 (1), 57 (2018). https://doi.org/10.21517/0202-3822-2017-41-1-57-64

35. A. V. Vertkov, I. E. Lyublinskii, and M. Yu. Zharkov, Plasma Phys. Rep. 44, 664 (2018). https://doi.org/10.1134/S1063780X18070073

36. G. Mazzitelli, M. L. Apicella, G. M. Apruzzese, F. Crescenzi, F. Iannone, G. Maddaluno, V. PericoliRidolfini, S. Roccella, M. Reale, B. Viola, A. V. Vertkov, and I. E. Lyublinski, J. Nucl. Mater. 463, 1152 (2015).

https://doi.org/10.1016/j.jnucmat.2014.12.050

37. M. Iafratti, M. L. Apicella, L. Boncagni, I. E. Lyublinski, G. Mazzitelli, and A. V. Vertkov, Fusion Eng. Des. 117, 157 (2017).

https://doi.org/10.1016/j.fusengdes.2017.02.005 
38. I. E. Lyublinski, A. V. Vertkov, M. Yu. Zharkov, V. V. Semenov, S. V. Mirnov, V. B. Lazarev, I. L. Tazhibayeva, G. V. Shapovalov, T. V. Kulsartov, A. V. D'yachenko, G. Mazzitelli, and P. Agostini, Fusion Eng. Des. 88, 1862 (2013).

https://doi.org/10.1016/j.fusengdes.2013.05.103

39. I. Tazhibayeva, G. Shapovalov, T. Kulsartov, Y. Ponkratov, I. Lyublinski, A. Vertkov, G. Mazzitelli, E. Azizov, and S. Mirnov, in Proceedings of the 25th IAEA Fusion Energy Conference, Saint Petersburg, 2014, Paper MPT/P8-13. Book of Abstracts, p. 712.

https://www-pub.iaea.org/MTCD/Meetings/PDFplus/2014/cn221/cn221 ProvisionalProgramme.pdf.

40. R. Dejarnac, J. Horacek, M. Hron, M. Jerab, J. Adamek, S. Atikukke, P. Barton, J. Cavalier, J. Cecrdle, M. Dimitrova, E. Gauthier, M. Iafrati, M. Imrisek,
A. Marin Roldan, G. Mazzitelli, et al., Nucl. Mater. Energy 25, 100801 (2020).

https://doi.org/10.1016/j.nme.2020.100801

41. J. Horacek, R. Dejarnac, J. Cecrdle, D. Tskhakaya, A. V. Vertkov, J. Cavalier, P. Vondracek, M. Jerab, P. Barton, G. van Oost, M. Hron, V. Weinzettl, D. Sestak, S. Lukes, J. Adamek, et al., Nucl. Mater. Energy 25, $100860(2020)$.

https://doi.org/10.1016/j.nme.2020.100860

42. S. Roccella, G. Dose, R. de Luca, M. Iafrati, A. Mancini, and G. Mazzitelli, J. Fusion Energy 39, 462 (2020).

https://doi.org/10.1007/s10894-020-00263-4

Translated by I. Grishina 